San Jose State University

SJSU ScholarWorks

$5-1-2000$

\title{
Attitudes, knowledge, and practice strategies of nurse practitioners in the state of California regarding complementary therapy
}

Steven J. Lenthe

San Jose State University

Follow this and additional works at: https://scholarworks.sjsu.edu/etd_projects

Part of the Other Nursing Commons

\section{Recommended Citation}

Lenthe, Steven J., "Attitudes, knowledge, and practice strategies of nurse practitioners in the state of California regarding complementary therapy" (2000). Master's Projects. 865.

DOI: https://doi.org/10.31979/etd.jxr7-29rf

https://scholarworks.sjsu.edu/etd_projects/865

This Master's Project is brought to you for free and open access by the Master's Theses and Graduate Research at SJSU ScholarWorks. It has been accepted for inclusion in Master's Projects by an authorized administrator of SJSU ScholarWorks. For more information, please contact scholarworks@sjsu.edu. 


\section{SAN JOSE STATE UNIVERSITY \\ SCHOOL OF NURSING}

\section{MASTER'S PROGRAM PROJECT OPTION (PLAN B) PROJECT SIGNATURE FORM}

STUDENT NAME

Steve Lenthe

SEMESTER ENROLLED Spring 2000

TITLE OF PROJECT Atitudes, Knowledge, and practice stratesies of nursepractitioners in the stete of Califarnia regarding complementary therepy

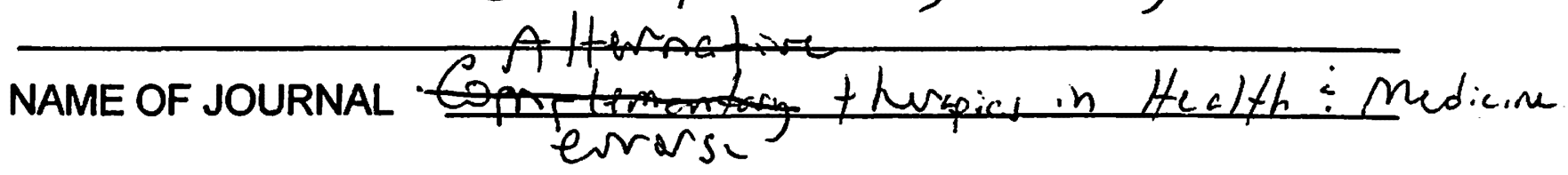

The project and manuscript have been successfully completed and meet the standards of the School of Nursing at San Jose State University. The project demonstrates the application of professional knowledge, clinical expertise, and scholarly thinking. An abstract of the project and two copies of the manuscript are attached.

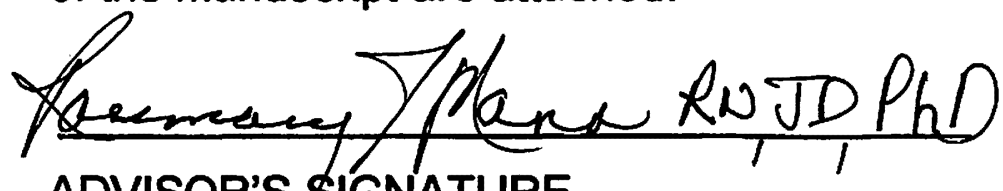

ADVISOR'S SIGNATURE

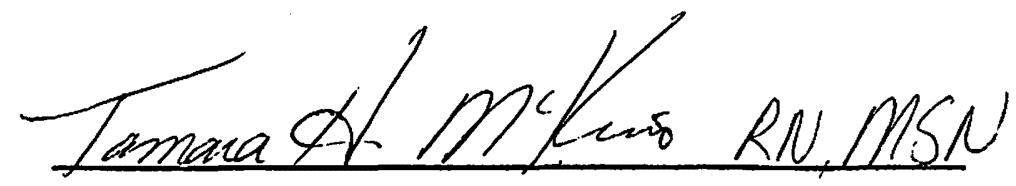

ADVISOR'S SIGNATURE

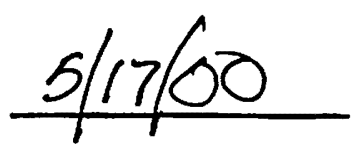

DATE

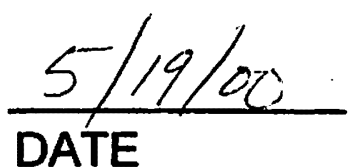

Please submit this form to the Graduate Coordinator. Attach abstract, two copies of the manuscript, and documentation of submission to the journal (i.e., postal receipt). 
Attitudes, knowledge, and practice strategies of nurse practitioners in the state of California regarding complementary therapy

\begin{abstract}

\section{Context}

This is a replication of a study by Boucher and Lenz (1) concerning knowledge and attitudes of physicians in a Midwestern teaching hospital about complementary therapy. Approval for use of all or any part of the original questionnaire was obtained from the authors.

\section{Objective}

To discover the attitudes, knowledge, and practice strategies related to complementary therapy by nurse practitioners in the state of California.

\title{
Design
}

The mail-in survey included basic demographic information, statements pertaining to understanding and use of complimentary therapy, evidence needed to evaluate efficacy, and preferred practice strategies. The instrument consisted of 34 questions. With the exception of the demographic information, all of the questions were taken from the original instrument verbatim.

\section{Participants}

A total of 300 nurse practitioners currently practicing in the state of California were randomly selected from a list provided by the California Coalition of Nurse Practitioners.

\section{Results}

One hundred and fifty four nurse practitioners completed surveys that were returned for a response rate of over $51 \%$. More than $68 \%$ of nurse practitioners in the survey felt that complementary therapy provided moderate to extreme benefit to the general public. Nearly $75 \%$ of respondents felt that a number of complementary therapies held future promise for the treatment of symptoms, conditions, and/or diseases. These same nurse practitioners also stated that they were likely to refer their clients to complementary therapists in the future.

\section{Conclusion}

Overall nurse practitioners view the combination of complementary therapies and allopathic medicine as beneficial to positive outcomes for their clients. Nurse practitioners in the State of California appear to be knowledgeable in the purposes of complementary therapy and motivated to use and/or refer clients to complementary therapists. 
ATTITUDES, KNOWLEDGE, AND PRACTICE STRATIGIES OF NURSE

PRACTITIONERS IN THE STATE OF CALIFORNIA REGARDING COMPLEMENTARY

THERAPY

Steven J. Lenthe RN MS FNP

San Jose State University

Rosemary J. Mann R.N. J.D. Ph.D.

Undergraduate Coordinator

School of Nursing, San Jose State University

Tamara McKinnon MSN

School of Nursing, San Jose State University

Correspondence concerning this manuscript and requests for reprints should be addressed to:

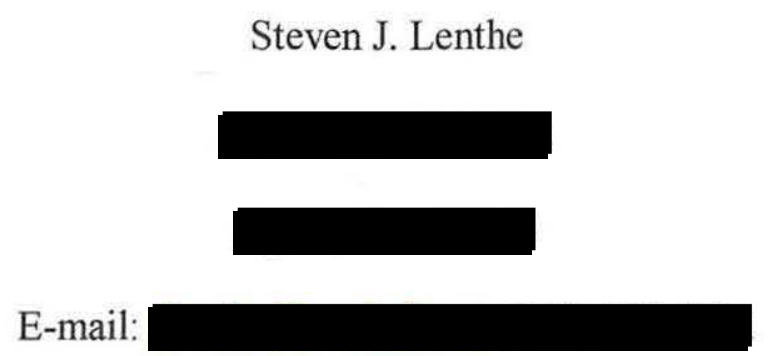


Attitudes, knowledge, and practice strategies of nurse practitioners in the state of California regarding complementary therapy

\section{ABSTRACT}

Context

This is a replication of a study by Boucher and Lenz (1) concerning knowledge and attitudes of physicians in a Midwestern teaching hospital about complementary therapy. Approval for use of all or any part of the original questionnaire was obtained from the authors.

\section{Objective}

To discover the attitudes, knowledge, and practice strategies related to complementary therapy by nurse practitioners in the state of California.

\section{Design}

The mail-in survey included basic demographic information, statements pertaining to understanding and use of complimentary therapy, evidence needed to evaluate efficacy, and preferred practice strategies. The instrument consisted of 34 questions. With the exception of the demographic information, all of the questions were taken from the original instrument verbatim.

\section{Participants}

A total of 300 nurse practitioners currently practicing in the state of California were randomly selected from a list provided by the California Coalition of Nurse Practitioners.

\section{Results}

One hundred and fifty four nurse practitioners completed surveys that were returned for a response rate of over $51 \%$. More than $68 \%$ of nurse practitioners in the survey felt that complementary therapy provided moderate to extreme benefit to the general public. Nearly $75 \%$ of respondents felt that a number of complementary therapies held future promise for the 
treatment of symptoms, conditions, and/or diseases. These same nurse practitioners also stated that they were likely to refer their clients to complementary therapists in the future.

\section{Conclusion}

Overall, nurse practitioners view the combination of complementary therapies and allopathic medicine as beneficial to positive outcomes for their clients. Nurse practitioners in the State of California appear to be knowledgeable in the purposes of complementary therapy and motivated to use and/or refer clients to complementary therapists. 


\section{INTRODUCTION}

The colloquialism 'some things change while some things remain the same' is easily applied to the direction of healthcare today. While the American public is actively seeking out alternatives to the medical profession for both primary health and preventative medicine, allopathic practitioners appear to be determined to stick with reductionist theory medicine. The practice of caring for and about people is a constantly changing endeavor, and as such, the general population no longer views healthcare as exclusive to visiting a practitioner of conventional medicine. Certain types of therapies that, not so very long ago, were considered quackery, are now more than just common place for many people. These therapies are essential to their total health and well being.

Multiple terms exist to describe such therapies. Unconventional or alternative therapy labels lead to a perception of being unproven, inadequate, or even dangerous. The recent trend towards the use of the term 'complementary therapy' $(1,2,3,4,5)$ provides for a feeling of coexistence that implies a working relationship between conventional medicine and complementary therapy (CT). CT can be loosely defined as any therapy not widely practiced by conventional health care practitioners and not widely taught in schools of allopathic medicine (1). It can also be said that they generally are not covered by the average health insurance policy.

The general population in the United States (US) is utilizing complementary therapies at an ever-increasing rate. In 1990 the number of visits Americans made to CT practitioners was higher than visits made to primary care providers (6). By 1997 the number of visits Americans made to complementary therapists was almost double that of primary care providers (7). That number is most certainly continuing to rise as more people evaluate the potential benefits of CT. 
Americans are also willing to pay nearly as much in out-of-pocket expenses for these services as compared with payments of services to primary care providers (7).

The utilization of CT crosses all socioeconomic boundaries (5). Multiple studies have shown that the general population both inside and outside the US has been utilizing a variety of CT's $(2,8,9,10)$. One such study in the US found that $25 \%$ of clients surveyed had utilized at least one form of complementary therapy in the previous year (10). This same study also found that $85 \%$ of clinicians surveyed held "the belief that many health problems could be more effectively treated using a holistic approach in lieu of a more conventional western approach" (10).

\section{Theoretical Prospective}

Holism has been suggested as a pseudonym for 'complementary' (11). The term 'holism', unfortunately, can mean many different things to many different individuals. For this reason it has been proposed that prior to using the term 'holism', the meaning of the term should be provided $(11,12)$. Patterson states that " holism will always be individualistic, based on the perception of what 'whole' is and where it ends; or whether we accept that it has an end" (11). Holism, as defined by Webster's dictionary, is "the view that an organic or integrated whole has an independent reality which can not be understood simply through understanding its parts" (13). Patterson chooses to avoid trying to define holism in that an exact description does not fit well with the ideals of individuality, but instead views holism as a philosophy or abstract thought that is only limited by "our existing consciousness" (12).

A new paradigm is being proclaimed in nursing, and it is holism. Johnson (14) conducted a bibliometric analysis of nursing literature dating back to 1966 and indeed found that the concept of holism is replacing that of scientific inquiry. Swackhamer has noted that for more 
then 20 years nursing has supported the view of 'whole-person healing', which is the foundation of holistic health as well as the foundation for many complementary therapies (5).

Nurse practitioners (NPs) are considered to be advanced specialist in nursing, and as such, tend to have a holistic attitude when it comes to the health and well being of their clients. This holistic attitude would seem to fit very well with the use of and or referral to complementary therapists by NPs. Therefore, the theoretical underpinnings for this survey will be based on the holistic prospective.

\section{Literature Review}

A tremendous amount of research has been done regarding the attitudes of physicians towards CT. Boucher and Lenz assessed the attitudes about and practice of complementary and alternative medicine (CAM) by physicians at Hennepin County Medical Center in Minneapolis, Minnesota (1). A total of 109 physicians working at least 20 hours per week completed the mailed questionnaire. The authors reported that $52.3 \%$ of physicians surveyed had referred a client to a complementary therapist, and that $48.1 \%$ of physicians felt that it was somewhat likely to extremely likely that they would refer in the future. The authors concluded that there is interest in the integration of CAM at Hennepin County Medical Center but that sufficient evidence of safety and efficacy remain important for overall acceptance by physicians.

A search of CINHL and Medline produced very little research regarding NPs attitudes and perceptions of complementary therapy. Gorden, Sobel, and Tarazona evaluated adult primary care clinician use and interest in CT (10). The study was conducted through a large health maintenance organization (HMO) in the State of California and the majority of respondents were physicians. However, the study did include a small percentage of what the authors refer to as obstetrics-gynecology NPs. The survey reported that $93 \%$ of respondents had 
provided for, or recommended to, clients at least 1 form of CT in the previous year. The authors concluded that there was moderate interest from the primary care providers (PCP) and obstetricgynecology clinicians to incorporate CT into this particular HMO setting (10).

Crock, Jarjoura, Polen, and Rutecki surveyed physicians attitudes towards CT in Stark county, Ohio (15). The study reported that only $28 \%$ of respondents referred clients to complementary therapists. The authors noted that physicians surveyed had developed preferences to certain therapies based on their experience with specific therapies. The authors also noted that, primarily among 'subspecialists', there was a risk that a client might be dropped as a result of the client utilizing CT instead of a prescribed medical treatment. The authors concluded that further peer review studies to determine efficacy of individual therapies would help increase referrals to complementary therapists.

Borkan, Neher, Anson, and Smoker evaluated physician referral rates and reasons for referral in Washington State, New Mexico, and southern Israel (16). The authors found that more than half of all physicians surveyed had referred a client to a complementary therapist once in the preceding year and that referral reasons were primarily client-driven. The authors concluded that primary care providers (PCP's) were the most likely to have knowledge of and personal experience with CT. The authors also found that PCP's were the most likely to make referrals to complementary therapists.

Berman, Singh, Lao, Singh, Ferentz, and Hartnoll studied physicians attitudes towards CT in the 'Chesapeake region' of the US (17). The authors found that of 18 proffered 'alternative medicine therapies', diet and exercise, behavioral medicine, counseling, psychotherapy, and hypnotherapy were considered legitimate medical practices by more than $90 \%$ of responding physicians. The authors also found that more than $50 \%$ of physicians would consider referring 
clients to nonphysicians for diet and exercise, counseling and therapy, biofeedback, and chiropractic services. Interestingly, although more than half of physicians surveyed felt that massage could be considered legitimate medical practice only $35 \%$ stated that they would refer clients to nonphysician practitioners and only $6.5 \%$ responded that they would refer clients to a physician for this service. Other forms of CT such as herbal medicine, homeopathy, and Oriental medicine were referred less than $6 \%$ of the time. The authors concluded that there is a high level of interest in many of the identified CT's and that the majority of physicians surveyed were interested in further training regarding these therapies.

\section{METHODOLOGY}

This study is a replication of research done by Boucher and Lenz (1) regarding the attitudes about and practice of CT by physicians in a Midwestern teaching hospital. The authors constructed their questionnaire by contacting individual researchers of previous studies and obtaining specific information regarding the instruments used. Boucher and Lenz then "modified" this information and produced a two-part questionnaire (1). A researcher-generated instrument without established reliability and validity was used because a standardized tool does not exist for these phenomena. The tool was assessed for face and content validity by a review of experts (1).

Approval for use of all or any part of the questionnaire in this study was obtained from the authors of the survey. The original questionnaire consisted of two parts. The first part requested basic demographic information and asked specific questions regarding opinions, familiarity, and experience with $\mathrm{CT}$. The second part requested specific information regarding actual use of CT at this Midwestern hospital (1). In communication with the authors regarding Part II it was concluded that the information obtained did not serve the purpose that they had 
originally intended and Part II was ultimately dropped from their reported findings.

Consequently, only Part I of the original instrument was used in this study.

Approval to perform the study was obtained from the San Jose State University Human Subjects-Institutional Review Board. The questionnaire was mailed to 300 nurse practitioners throughout the State of California randomly chosen from a list obtained from the California Coalition of Nurse Practitioners. A cover letter accompanied the questionnaire that stated that participation was voluntary and informed consent was implied with completion of the questionnaire. The surveys were mailed at the beginning of February 2000 with a return request in one month. One hundred and fifty-four surveys were returned for a response rate of over $51 \%$. Data from the surveys were entered into a SPSS program.

\section{RESULTS}

\section{Demographics}

The majority of respondents $(78.6 \%, n=121)$ were masters educated NP's (Table 1), with $13.6 \%(n=21)$ reporting bachelors degrees and $2.6 \%(n=4)$ of respondents stating their education level at a Ph.D. A total of $63.6 \%(n=98)$ respondents were family NP's, $11.0 \%(n=17)$ adult NP's, 7.8\% $(n=12)$ geriatric NP's, 6.4\% $(n=10)$ women's health NP's, and $5.8 \%(n=9)$ pediatric NP's. Other write-ins included acute care/cardiopulmonary, occupational health, emergency medicine, and dermatology. The average age was 46.9 years with 6 respondents choosing not to enter any number. The respondents reported an average work experience of 9 years with 1 missing response. The survey respondents were predominantly Caucasian at $87.0 \%(n=134)$, with $8.4 \%(n=13)$ Asian, $3.2 \%(n=5)$ Hispanic, and 1 Pacific Islander (0.6\%). The respondents were also predominantly female $(91.4 \%, n=140)$, with $3.9 \%(n=6)$ male. Sixty-one respondents (40\%) reported that they had worked for an organization that offered CT. 


\section{Attitudes and Perceptions}

In response to the question "Which of the following statements most closely represents your feelings about complementary therapy?" 73.4\% (Table 2) of NP's chose "While we need to be cautious in our claims, a number of complementary therapies hold promise for the treatment of symptoms, conditions, and/or diseases." Very few NP's (1.9\%) responded "While a few complementary modalities may have limited health benefits, I believe that complementary therapy has no true impact on the treatment of symptoms, conditions, and/or diseases." A total of $11.7 \%$ of NP's chose the response "Complementary therapy has the potential to revolutionize allopathic medical treatment." One NP felt that CT is quackery, and 5.2\% of NP's had no strong feelings about CT.

\section{Attitude Regarding Effectiveness}

Attitudes of NP's regarding evaluating evidence of the effectiveness of CT were demonstrated by one question that was based on a 5-point Likert scale (Table 3). Participants were asked to rank 9 different types of evidence from 1= "no impact on thoughts"; $2=$ "would catch my attention but have no impact"; $3=$ "would look at more favorably but not consider proof"; $4=$ "would convince me it is somewhat effective"; to $5=$ "would convince me it is highly effective". Prospective randomized controlled clinic trials ranked highest (mean $=4.23$ ).

Evidence demonstrating a treatment's physiologic mechanism ranked second (mean $=3.96)$ and personal experience ranked third (mean $=3.89)$. At the bottom were recommendations from family or friends (mean $=3.26)$ and case reports in CT journals (mean $=3.02)$. 


\section{Attitudes Regarding Benefits}

More than half (68.2\%) of the NP's felt that CT offered moderate to extreme benefit to the health of the public, while not one NP felt there was an extreme threat (Table 4). More than $10 \%$ of NP's felt that there was a moderate threat to the public while $11.7 \%$ felt that there would be no effect on the public what so ever. More than $85 \%$ of NP's felt that the incorporation of CT into their clinic/setting would have some positive to major positive impact on client satisfaction.

\section{Attitudes Regarding Outcomes}

Respondents were asked whether use of CT produced favorable to unfavorable treatment outcomes. More than $81 \%$ of NP's $(n=119)$ felt that the use of CT would provide some positive to major positive outcomes, only $4.7 \%(n=7)$ of respondents felt that there would be negative outcomes. A total of $7.5 \%(n=11)$ of respondents felt that neither positive nor negative outcomes were expected, and 9 respondents did not know (Table 5).

\section{Attitudes Regarding Impact On Career}

The survey asked NP's what impact utilization of CT might have on their careers. More than half $(57.6 \%)$ of respondents felt that it would have some positive to major positive impact, and $40 \%$ of respondents felt that their current professional and administrative climates were favorable to extremely favorable towards the use of CT. Most NP's felt no pressure, either financial or professional, to utilize or not utilize CT.

\section{Knowledge}

The question was posed, "To what extent do you agree or disagree that nurse practitioners should have knowledge about the most prominent complementary therapies?" NP's stated that they strongly agreed with this statement $(57.1 \%, n=88$, Table 6$)$. Thirty-seven percent 
of respondents stated they agreed with the statement, and no NP's disagreed with the statement (Table 6).

A number of written comments were made regarding this question. Several respondents remarked that clients can benefit from the holistic nature of CT. Most respondents stated that being knowledgeable with regards to CT was beneficial to the client. One respondent put it most succinctly stating "whether we agree or not, patients are using complementary therapies and we need to make sure the therapies really are complementary and not contraindicated."

\section{Self Report of Knowledge}

All of the respondents were given an opportunity to express their level of understanding of each of the 8 listed modalities (Table 7). This was done through a Likert scale where 1= "I am unfamiliar with this term", 2="I have a rudimentary understanding of this therapy", and 3="I understand the proposed medicinal uses of this therapy". Based on the mean results, massage ranked highest $($ mean $=2.66)$. This was followed by acupuncture and chiropractic $($ mean $=2.53)$, herbal medicine $($ mean $=2.44)$, biofeedback $($ mean $=2.42)$, vitamin therapy $($ mean $=2.39)$, homeopathy $($ mean $=2.26)$, and touch therapy $($ mean $=2.22)$.

\section{Lectures and Training}

A large percentage $(70.1 \% \mathrm{n}=108)$ of respondents stated that they had attended lectures or workshops on, or received training in the use of CT's. The topics included all of the listed modalities and several write in modalities. Herbal medicine received the highest number of responses $(n=61)$, followed by touch therapy $(n=36)$, acupuncture $(n=28)$, massage $(n=30)$, vitamin therapy $(n=23)$, biofeedback $(n=19)$, homeopathy $(n=16)$, and chiropractic $(n=9)$. There were another 29 write in responses, including accupressure $(n=7)$, meditation $(n=4)$ Lomi Somatics, guided imagery $(n=2)$, breath work, hypnosis $(n=2)$, "mind body spirit", ayurveda, 
"Oriental medicine", yoga $(n=2)$, Reiki, "Chinese medicine" $(n=3)$, colon hydrotherapy, naturopathy, bee venom therapy, magnet therapy, shiatsu, aroma therapy $(n=2)$, Bach flower remedies.

The question was asked, "Have you completed a training program or are you certified in the use of any complementary therapy?" There were 16 positive responses to this question. When asked to indicate in which modalities 4 responses reported massage, 2 responses reported biofeedback, and 7 responses reported touch therapy. There were several write in responses including meditation, guided imagery, bodywork, jin shin jyutsu, colon hydrotherapy, and chelation therapy.

\section{Practice Strategies}

A total of $87.0 \%(n=134)$ of respondents stated they discussed potential benefits with clients. Of this total, $37 \%(n=57)$ stated that they initiated the discussion, and $39 \%(n=60)$ stated that the client initiated the discussion. More than $82 \%(n=127)$ of NP's discussed potential harmful effects of CT with clients. Of this total, $63.0 \%(n=97)$ stated that they initiated the discussion and $21.4 \%(n=33)$ stated that the client initiated the discussion.

\section{Referral Stratigies}

The respondents were asked about their philosophy regarding referral of clients to complementary therapists (Table 8). When asked, "Have you ever referred a client to a complementary therapist?', $68.2 \%(n=105)$ of NP's reported that they had referred a client to a complementary therapist. When asked if they would do so in the future, a combined $72.7 \%$ $(n=112)$ of NP's stated it would be somewhat likely or extremely likely they would refer clients.

Respondents were asked how frequently they recommended clients try or referred clients to a complementary therapist. A total of $59.5 \%(n=88)$ NP's stated that they recommended CT or 
referred clients to a complementary therapist. These respondents were then asked to check all that applied from 5 possible reasons for referring clients to complementary therapists (Table 9). More than $44.8 \%(n=69)$ stated strong interest from clients in being referred as a reason; $38 \%$ $(n=59)$ chose beneficial personal experience as a reason; $25.3 \%(n=39)$ chose that they know a complementary therapist with a solid reputation as a reason; $17.5 \%(n=27)$ chose as a last resort for clients with chronic or terminal ailments as a reason; $16.9 \%(n=26)$ chose to write in other statements, and $8.4 \%(\mathrm{n}=13)$ chose recommending and/or referring for non-specific complaints as a reason.

The survey asked respondents about specific discussions with clients regarding risks and benefits of CT. Ninety-three percent of respondents stated that they discussed the potential benefits of CT with $37.0 \%$ stating they initiated and $39.0 \%$ stating the client initiated the discussion. More than $84 \%$ of NP's reported that they discussed possible harmful effects with clients. Sixty-three percent of NP's stated that they initiated while only $21.4 \%$ indicated that the client initiated the discussion.

There were many drawbacks sited by the respondents regarding the use of CT. Money was the most often cited reason, either through lack of insurance coverage or the relatively high cost of individual CT's. Lack of physician approval for such referrals was also cited.

\section{Comparing Physicians and NP's}

Physician demographics from the CAM study are noted in table 10 . The demographic makeup is somewhat different between the two groups. The CAM study is composed of predominately white males. The average time in health services for the physicians in the CAM study is 18.6 years (1). 
Specific statistical comparison of the two groups was not possible because the raw data from the initial study was not available. Regardless, certain significant differences were noted in the results of the two studies. While a large percentage of physicians $(65.1 \%, n=71)$ felt that many complementary therapies held promise very few physicians $(3.7 \%, n=4)$ felt that CT had the potential to revolutionize allopathic medicine (Table 2). A higher percentage of NP's felt that many CT's held promise $(73.4 \%, \mathrm{n}=113)$, and a larger percentage felt that $\mathrm{CT}$ had the potential to revolutionize allopathic medicine $(11.7 \%, \mathrm{n}=18)$.

Another area of significant difference between physicians and NPs was noted in the perceived threat or benefit to the public (Table 4). While $6.4 \%(n=7)$ of physicians felt that there was extreme benefit, a much larger percentage of NP's felt that there was an extreme benefit to the public $(17.5 \%, \mathrm{n}=27)$.

More NPs viewed CT as producing favorable outcomes. A total of $77.3 \%(n=119)$ of NP's felt that there would be 'some' to 'major' positive outcomes for clients compared to $59.6 \%$ $(n=66)$ of physicians. A much larger percentage of NP's as compared with physicians responded that they strongly agreed that they should have knowledge of the most prominent CT's (Table 6). A larger percentage of NP's had referred clients in the past ( $68.2 \%$ vs. $52.3 \%$ of physicians) and more NP's felt that it was somewhat likely to extremely likely that they would refer clients in the future $(72.8 \%$ vs. $48.1 \%)$.

\section{LIMITATIONS}

Specific limitations include the use of an instrument that has not been tested for validity and reliability beyond face validity. The overall study would be enhanced if specific statistical analyses could be done between the NP's results and the physicians' results. Despite assertions by Boucher and Lenz (1) that the physicians surveyed in their study resided in an area of the 
country more accepting of CT than other areas, any comparisons between the two groups must be tempered with the knowledge that the two geographic regions are different. Further research into the specific geographic differences was not done.

As with the original study, there were no specific definitions given for $\mathrm{CT}$, leaving it open to each individual to form his or her own conclusions. Statistical analysis of the data was generally limited by the specific coding in the SPSS program. These limitations are somewhat tempered by the size of the population and the use of a random sample. The ability to obtain more thorough demographic information also allowed for the possibility to perform more complex statistical analyses.

\section{DISCUSSION}

Nurse practitioners in the State of California strongly approve of the use of complementary therapies in conjunction with western medicine. Although they see some importance in traditional reductionist theory results, NP's seem to be more likely than physicians to view personal experience with a particular CT as appropriate criteria for evaluating its performance. Nurse practitioners are also more likely to recommend or refer clients to CT based on their own personal experience with CT. Nurse practitioners feel that the integration of CT with western medicine would bring about positive outcomes and increased satisfaction for their clients.

Nurse practitioners view knowledge of CT as a very important part of holistic care for their clients. NP's also demonstrate a high level of understanding of individual therapies as well as a desire to further their understanding through workshops and lectures. Most importantly, the vast majority of NP's feel that it is their responsibility to discuss both potential benefits as well as risks from the utilization of $\mathrm{CT}$. 


\section{IMPLICATIONS}

The purpose of this study is to better understand the attitudes, knowledge, and practice strategies of NP's regarding complementary therapy. There is no intent to give credibility to the unfortunate proliferation of charlatans that would profit at the expense of unwitting clients. It is for this very reason that NP's must be informed of the choices that their clients are making with or without their knowledge. NP's must take the initiative to discuss these therapies in a nonthreatening manner for the purpose of developing a discourse with the client and, if necessary, the complementary therapists that have as their goal the health and well being of the client.

The direction that NP's in the State of California must now take is to further their education regarding CT's by attending lectures and classes. To date, only the UCSF School of Nursing NP program is incorporating instruction of certain complementary therapies into its curriculum (18). As CT continues to increase in popularity Schools of Nursing at all educational levels must seek to incorporate CT into their curriculum. Further research should be directed at identifying specific disease processes that can benefit from $\mathrm{CT}$ and establishing goals to obtain the appropriate and desired outcomes. Pressure needs to be put forth on legislators and insurance companies to incorporate coverage of the most widely used and accepted forms of CT. Certainly in the state of California, NP's are in the position to take advantage of the high number of CT's that are available, and work with these therapists as well as their clients to promote a holistic environment in which increased health and wellness is the goal. 


\section{References}

1. Boucher TA, Lenz SK. An organizational survey of physicians attitudes about and practice of complementary and alternative medicine. Altern Ther Health Med 1998;4:59-65.

2. Grenfield A, Patel N, Robinson N. Complementary therapy: General practitioners' referral and patients' use in a multi-ethnic area. Complement Ther Med $1998 ; 6: 127-32$.

3. Kuhn, MA. Complementary therapies for health care providers. Philadelphia: Lippincott Williams \& Wilkins; 1999.

4. Rankin-Box, D. Therapies in practice: A survey assessing nurses' use of complementary therapies. Complementary Therapies in Nursing \& Midwifery 1997;3:92-9.

5. Swackhamer, A. Complementary Therapies: It's Time to Broaden Our Practice. RN 1995;58:49-51.

6. Eisenberg DM, Kessler RC, Foste C, Norlock FE, Calkins DR, Delbanco TL. Unconventional medicine in the United States. Prevalence, costs, and patterns of use. N Engl J Med 1993;328:246-52.

7. Eisenberg DM, Davis RB, Ettner SL, Appel S, Wilkey S, Van Rompay M, Kessler RC Trends in alternative medicine use in the United States, 1990-1997: results of a follow-up national survey. 1998;280(18):1569-75.

8. Kelvinson R, Payne S. Decisions to seek complementary medicine for pain: A controlled study. Complement Ther Med 1993;1:2-5.

9. Emslie M, Campbell M, Walker K. Complementary Therapies in a local healthcare setting. Part 1: Is there real public demand? Complement Ther Med 1996;4:39-42. 
10. Gordon NP, Sobel DS, Tarazona EZ. Use of and in alternative therapies among adult primary care clinicians and adult members in a large health maintenance organization. West J Med 1998;169:153-61.

11. Patterson EF. The philosophy and physics of holistic health care: Spiritual healing as a workable interpretation. J Adv Nurs 1998;27:287-93.

12. Baum M. What is holism? The view of a well-known critic of alternative medicine. Complement Ther Med 1998;6:42-4.

13. Webster's New World dictionary. $3^{\text {rd }}$ ed. 1998. New York: Simon \& Schuster.

14. Johnson MB. The holistic paradigm in nursing: The diffusion of an innovation. Res Nurs Health 1990;13:129-39.

15. Crock RD, Jarjoura D, Polen A, Rutecki GW. Confronting the communication gap between conventional and alternative medicine: A survey of physicians' attitudes. Altern Ther Health Med 1999;5:61-6.

16. Borkan J, Neher JO, Anson O, Smoker B. Referrals for alternative therapies. J Fam Pract 1994;39:545-50.

17. Berman BM, Singh BK, Lao L, Singh BB, Ferentz KS, Hartnoll SM. Physicians' attitudes toward complementary of alternative medicine: A regional survey. Altern Med 1995;8:361-6. 18. Sussman B. Holistic health: NP program at UCSF first to include alternative therapies in curriculum. Nurseweek 2000 April 10;13(8):31. 
Table 1

Nurse Practitioner Demographics $(\mathrm{n}=154)$

Age: $\quad$ Mean age $=46.9$ years $(+/-8.7$ years $), \operatorname{Min}=24, \operatorname{Max}=76$

Gender.

Female

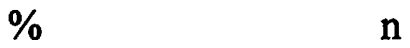

Male

95.9

140

Missing

4.1

6

Ethnicity

Caucasian

87.6

134

Hispanic

3.3

5

Asian

8.5

13

Pacific Islander

0.7

1

Educational Preparation

BS

13.6

21

MS

78.6

121

$\mathrm{Ph} . \mathrm{D}$

2.6

4

Other

5.2

8

Clinical Specialty

FNP

63.6

98

ANP

11.0

17

GNP

7.8

12

Obgyn

6.4

10

PNP

5.8

9

Work experience (years)

0-9

62.1

95

10-19

18.3

28

20-29

19.6

30

Mean work experience $9.1(+/-8.3)$ 
Table 2

Nurse practitioners attitudes regarding complementary therapy

\begin{tabular}{lccc} 
& & & Boucher \& \\
Statements & Agree & $\%$ & Lenz \% (1)* \\
\hline CT is Quackery & 1 & 0.6 & 0.9 \\
CT will have no impact & 3 & 1.9 & 12.8 \\
No strong feelings about CT & 8 & 5.2 & 11.0 \\
Cautious in claims about CT & & & \\
but some hold promise & 113 & 73.4 & 65.1 \\
CT has the potential to & & & \\
revolutionize allopathic medicine & 18 & 11.7 & 3.7 \\
Other & 7 & 4.5 & 5.5 \\
Missing & 4 & 2.6 & 0.9 \\
*Data from Boucher \& Lenz (1): Permission to reprint obtained from InnoVison \\
communications
\end{tabular}


Table 3

Evaluation of methods to determine effectiveness of CT

Boucher \&
Category
Lenz (1)*

$\begin{array}{lccccccc}\text { Types of evidence } & 1 & 2 & 3 & 4 & 5 & \text { Mean } & \text { Mean\&Rank } \\ \text { Prospective } & 1 & 4 & 16 & 63 & 60 & 4.23 & 4.351^{\text {st }} \\ \text { Physiologic } & 0.7 \% & 2.8 \% & 11.1 \% & 43.8 \% & 41.7 \% & & \\ & 1 & 3 & 29 & 79 & 32 & 3.96 & 3.872^{\text {nd }} \\ \text { Personal } & 0.7 \% & 2.1 \% & 20.1 \% & 54.9 \% & 20.8 \% & & \\ & 1 & 4 & 36 & 71 & 32 & 3.89 & 3.314^{\text {th }} \\ \text { Retrospective } & 0.7 \% & 2.8 \% & 25.0 \% & 49.3 \% & 22.2 \% & & \\ & 3 & 8 & 23 & 90 & 20 & 3.81 & 3.403^{\text {rd }} \\ \text { Specialist } & 2.1 \% & 5.6 \% & 16.0 \% & 62.5 \% & 13.9 \% & & \\ & 4 & 7 & 30 & 83 & 19 & 3.74 & 3.115^{\text {th }} \\ \text { Standard Case } & 2.8 \% & 4.9 \% & 21.0 \% & 58.0 \% & 13.3 \% & & \\ & 2 & 11 & 30 & 78 & 17 & 3.67 & 3.046^{\text {th }} \\ \text { Colleagues } & 1.4 \% & 7.6 \% & 25.0 \% & 54.2 \% & 11.8 \% & & \\ & 1 & 10 & 47 & 71 & 15 & 3.61 & 2.987^{\text {th }} \\ \text { Family } & 0.7 \% & 6.9 \% & 32.6 \% & 49.3 \% & 10.4 \% & & \\ & 3 & 16 & 67 & 56 & 2 & 3.26 & 2.688^{\text {th }} \\ \text { CT case reports } & 13 & 24 & 59 & 41 & 6 & 3.02 & 2.099^{\text {th }} \\ & 9.1 \% & 16.8 \% & 41.3 \% & 28.7 \% & 4.2 \% & & \end{array}$

*Data from Boucher \& Lenz (1): Permission to reprint obtained from InnoVison communications 
Table 4

Threat or benefit of CT to public as perceived by NP's

Threat or benefit

Extreme threat

Moderate threat

Neither/nor

Moderate benefit

Extreme benefit

Don't know

Missing n

0

16

18

74

27

13

6
$\%$

0.0

10.8

12.2

50.0

18.2

8.4

3.9
Boucher \& Lenz \% (1)*

0.9

15.6

18.3

41.3

6.4

15.6

1.8

*Data from Boucher \& Lenz (1): Permission to reprint obtained from InnoVison communications 
Table 5

Favorable vs Unfavorable Treatment Outcomes

$\begin{array}{lll}\text { Statement } & \mathrm{n} & \% \\ \text { Major positve outcomes } & 22 & 14.3 \\ \text { Some positve outcomes } & 97 & 63.0 \\ \text { Neither/nor } & 11 & 7.1 \\ \text { Some negative outcomes } & 6 & 3.9 \\ \text { Major negative oucomes } & 1 & 0.6 \\ \text { Don't know } & 9 & 5.8 \\ \text { Missing } & 8 & 5.2\end{array}$


Table 6

NP reported need for knowledge of CT

$\begin{array}{lccc}\text { Knowledge statement } & \text { n } & \% & \text { Boucher \& Lenz \% (1)* } \\ \text { Strongly agree } & 88 & 57.1 & 26.6 \\ \text { Agree } & 58 & 37.1 & 58.7 \\ \text { Neither/nor } & 6 & 3.9 & 9.2 \\ \text { Disagree } & 0 & 0 & 0 \\ \text { Strongly disagree } & 0 & 0 & 0 \\ \text { Don't know } & 1 & 0.6 & 3.7 \\ \text { * Data from Boucher \& Lenz (1): Permission to reprint obtained from InnoVison } & \\ \text { communications } & & \end{array}$


Table 7

Self-report of knowledge of CT's by NP's

Boucher \& Lenz (1)

\begin{tabular}{|c|c|c|c|c|c|c|c|c|c|}
\hline \multirow[t]{2}{*}{ Modality } & \multicolumn{2}{|c|}{1} & \multicolumn{2}{|c|}{2} & \multicolumn{2}{|c|}{3} & \multirow[t]{2}{*}{ Mean } & \multirow{2}{*}{\multicolumn{2}{|c|}{$\begin{array}{c}\text { mean } \\
\text { and rank* }\end{array}$}} \\
\hline & $\mathbf{n}$ & $\%$ & $\mathrm{n}$ & $\%$ & $\mathrm{n}$ & $\%$ & & & \\
\hline Massage & 4 & 2.6 & 41 & 27.2 & 106 & 70.2 & 2.66 & 2.24 & $4^{\text {th }}$ \\
\hline Acupuncture & 5 & 3.3 & 61 & 40.4 & 85 & 56.3 & 2.53 & 2.33 & $3^{\text {rd }}$ \\
\hline Chiropractic & 6 & 4.0 & 59 & 39.3 & 85 & 56.7 & 2.53 & 2.38 & $2^{\text {nd }}$ \\
\hline Herbal & 13 & 8.7 & 65 & 43.3 & 72 & 48.0 & 2.44 & 2.05 & $5^{\text {th }}$ \\
\hline Biofeedback & 6 & 4.0 & 75 & 49.7 & 70 & 46.4 & 2.42 & 2.47 & $1^{\text {st }}$ \\
\hline Vitamin therapy & 3 & 2.0 & 78 & 51.7 & 70 & 46.4 & 2.39 & 2.01 & $6^{\text {th }}$ \\
\hline Homeopathy & 10 & 6.7 & 90 & 60.4 & 49 & 32.9 & 2.26 & 2.00 & $7^{\text {th }}$ \\
\hline Touch therapy & 17 & 11.3 & 83 & 55.3 & 50 & 33.3 & 2.22 & 1.60 & $8^{\text {th }}$ \\
\hline
\end{tabular}


Table 8

Referral Strategies of NP's

Have you referred?

Yes

No

N/A

Missing

Will you refer in future?

Extremely likely

Somewhat likely

Neither/nor

Somewhat unlikely

Extremely unlikely

Don't know

N/A

Missing
42

70

10

19

9

1

2

1
$\%$

68.2

26.6

3.9

1.3

2

$41 \quad 26.6$

6

1.3


Table 9

NP reasons for recommending or referring clients to CT's

Reason

Clients expressed interest

Personal experience

Know therapist with a

solid reputation

Clients last resort

Non-specific complaints

Other
26

$\%$ responses*

\section{8}

38.3

39

25.3

27

17.5

13

8.4

16.9

* Based on a total of 88 responses 
Table 10

Boucher \& Lenz (1) demographics

Physicians from Midwestern hospital $(n=109)$

Physician type

Primary care*

Specialist

* Includes family practice, general medicine, internal medicine, ob/gyn, pediatrics, and primary

care outreach

Gender

Female

Male

Ethnicity

Caucasian

Other

Age mean $=46.9+/-9$

Number of years employed in health services $\mathbf{1 8 . 6}$
27

73

$105 \quad 96.3$

4

3.7 